\title{
ESTUDIO SOBRE GÉNERO Y LA DIVERSIDAD SEXUAL EN LAS FUERZAS ARMADAS DE BRASIL
}

\author{
STUDY ON GENDER AND SEXUAL DIVERSITY IN THE BRAZILIAN ARMED FORCES
}

\author{
Douglas Verbicaro Soares
}

Universidade Federal de Roraima, Boa Vista, RR, Brasil. E-mail: douglas_verbicaro@yahoo.com.br

DOI: https://doi.org/10.46550/amormundi.v2i6.128

Recebido em: 12.10.2021

Aceito em: 20.11.2021

\begin{abstract}
Resumen: El presente estudio tiene por objetivo visibilizar los problemas enfrentados por diversas personas motivados por discriminación de género/orientación sexual dentro de las Instituciones Militares de Brasil. Se realizó una investigación bibliográfica, utilizando el método deductivo y el análisis cualitativo. El estudio concluye por la perpetuación de prácticas que dificultan el respeto de los Derechos Humanos. Por lo tanto, se necesitan esfuerzos continuos para permitir la protección y el cumplimiento reales de los derechos comentados, en favor de una sociedad más justa, igualitaria y solidaria, sin discriminaciones, en especial sobre sexualidad y género.
\end{abstract}

Palabras clave: Derechos Humanos. Protección. Igualdad. Militar. Discriminación.

\begin{abstract}
This study aims to make visible the problems faced by people motivated by gender/sexual orientation discrimination within the Military Institutions of Brazil. A bibliographic research was carried out, using the deductive method and qualitative analysis. The study concludes by the perpetuation of practices that hinder the respect of Human Rights. Therefore, continuous efforts are needed to allow the real protection and fulfillment of the rights mentioned, in favor of a more just, egalitarian and supportive society, without discrimination, especially on sexuality and gender.
\end{abstract}

Keywords: Human Rights. Protection. Equality. Military. Discrimination.

\section{Introducción}

Cn éste estudio se trabajará la idea de que el género y la orientación homosexual no
deberán ser entendidos como algo limitador, que impida la realización de cualquier actividad cotidiana en sociedad. Se notará que tener esas condiciones no representa un riesgo para la sociedad y, además, no es factor de impedimento de cualquier tipo de actividad profesional. En éste sentido, la investigación retratará que la homosexualidad no es en sí un factor de exclusión para la participación de personas con ésta orientación dentro de las Fuerzas Armadas brasileńas, lo mismo argumento será utilizado para trabajar con el tema de las mujeres dentro de las Instituciones militares.

Partiendo de estas ideas preliminares, el presente estudio buscará enfocar que, por más 
que las personas hayan evolucionado en las sociedades a lo largo de los tiempos, conviviendo con el surgimiento de variados aparatos formales de protección, todavía es importantes más investigación sobre la integración de la diversidad sexual y de género en los espacios militarizados.

Por esta razón, el problema del presente estudio estará en verificar/fiscalizar la adecuación de preceptos normativos a un efectivo cumplimiento de su esencia en las más variadas formas y estructuras presentes en una sociedad. Es decir, que los preceptos normativos creados en un determinado momento histórico pueden sufrir algún tipo de imperfección en sus estructuras basilares, lo que permitiría el cometimiento de violaciones motivadas por su vez en idearios de perjuicio, discriminaciones y en la imposibilidad de tener reconocido un trato igualitario entre las personas. Muchas son las personas victimadas en la sociedad brasileña principalmente en los temas de la sexualidad y al respecto a las libertades sexuales. ${ }^{1}$

El trabajo preguntará por los motivos que llevan a ese posicionamiento por la aceptación o denegación de una persona homosexual dentro de las Instituciones militares de Brasil. Se buscará en el presente ensayo demostrar las realidades vividas dentro de las Fuerzas Armadas de Brasil, en lo que se relaciona a la orientación del deseo homosexual, así como los miedos de la incorporación de esas personas con esa diversidad sexual manifestada, cómo también, retratar las opiniones a favor y contrarias a esa incorporación.

De este modo, serán expuestos, también, los casos de militares que prefieren no asumir sus condiciones de homosexuales y acaban viviendo abusos diariamente (directa o indirectamente) dentro de las Fuerzas Armadas. En la experiencia brasileña, cuando una persona resuelve asumir su orientación del deseo frente a la Institución militar, acaba siendo penada, o convertida en víctima de bromas o acosada por tener esa orientación. ${ }^{2}$

El estudio viabilizará ejemplos de militares que tienen una orientación homosexual y que fueron víctimas de sus propios compañeros de trabajo o por la Institución militar a la cual pertenecían.

Estos casos están presentes en leyes presentes en artículos del Código Militar de Brasil, o por normas de conducta militares, juegos jocosos, entrenamientos y sus cantigas discriminatorios, o castigos realizados dentro de la Organización Militar $^{3}$ o, en la simple exclusión de esa persona con una orientación homosexual, que se ve obligada a esconder o negar, en algunos casos, su propia identidad sexual, siendo así posiblemente perjudicial a su salud física y mental ${ }^{4}$, lo que impide a esas personas que asumir y vivir de manera digna y justa.

El estudio optará por especificar la situación de la homosexualidad en las Fuerzas Armadas de Brasil. Debido a la grande cuantidad de casos con denotación anti-homosexual existentes en este país americano, como por ejemplo, con el caso brasileño de la pareja militar homosexual (Laci de Araújo y su compañero sentimental) en sociedad en el año de 2008. ${ }^{5}$

La temática de la homosexualidad en las Fuerzas Armadas se presenta como para

1 R. RAUPP RIOS, "Homofobia na perspectiva dos direitos humanos e no contexto dos estudos sobre preconceito e discriminação" en R. Diniz Junqueira, Diversidade Sexual na Educação: problematizaçôes sobre a homofobia nas escolas. Brasília, Brasil, Coleção Educação para todos, 2009, pp. 69-73.

2 F. ALCÂNTARA FIGUEIREDO, Soldados não choram: a vida de um casal homossexual no Exército do Brasil. Depoimento a Roldão Arruda. São Paulo, Brasil, Editora Globo, 2008, pp. 154-61.

3 M. C. D' ARAUJO, Pós-modernidade, sexo e gênero nas Forças Armadas. Rio de Janeiro, Brasil, p. 72. Disponible en: $<$ http://www.ndu.edu/chds/journal/PDF/2003/dAraujo-essay.pdf>. Consulta en: 20 de noviembre de 2021.

4 F. LÓPEZ SÁNCHEZ, Homosexualidad y familia. Lo que los padres, madres, homosexuales y profesionales deben saber y hacer. 1a Edición, Barcelona. España, Editorial GRAÓ, junio de 2006, pp.67-8.

5 F. ALCÂNTARA FIGUEIREDO, op. cit., pp. 15-25. 
la protección de las libertades sexuales como parte de esos derechos necesarios, una vez que representa relevo no solamente para la esfera regionalizada de un país o sociedad (en este caso en Brasil), pero también, presentarlo como viable para la sociedad internacional, una vez que la temática de la homosexualidad está presente en variadas partes y, las experiencias vividas por los homosexuales militares, sea en Brasil o en otros países, merecen ser entendidas en los más diversos sectores (económico, político, social y cultural).

Para el marco teórico y metodológico del estudio, hemos optado por un enfoque de diversas disciplinas, una vez que el tema exige una mayor complejidad, siendo que las ciencias sociales serán destacadas en el trabajo, como por ejemplo, las ciencias jurídicas, la psicología. Es significante recordar que el estudio inicial está direccionado para las ciencias jurídicas y por la utilización de medios inductivos (comparación de los hechos sociales y el propio trabajo, generando una idea final sobre su contenido) y deductivos (medio que utiliza la deducción para llegar a un entendimiento posterior sobre el estudio, en este sentido se notará el empleo del derecho de modo visibilizado (normas nacionales e internacionales) con los hechos sociales de menor proporción.

Se ha utilizado de modo predominante una metodología cualitativa. Es válido recordar que el primero instrumento utilizado, basado en la investigación de documentos, bibliografías, entrevistas distintas, artículos de la red mundial de ordenadores, libros publicados. Las entrevistas utilizadas han sido sacadas tanto de artículos publicados o posibilitadas por el envío del material por internet (dirección electrónica) del realizador del estudio, realizadas con personas anónimas, que irán a auxiliar la investigación. ${ }^{6}$

La finalidad de este estudio fue buscar instrumentos para permitir la integración, la igualdad de trato entre hombres y mujeres, y de la diversidad sexual en la propia sociedad brasileña, desarrollando y enseńando como afrontar los problemas sufridos por grupos minoritarios que forman parte, buscando la reducción de las desigualdades de trato entre los ciudadanos y, también, las situaciones de injusticias.

El presente trabajo tiene por objetivo de relacionar en papel de las mujeres o de personas con una orientación homosexual dentro de las Instituciones militares brasileñas. Organizaciones estas que están marcadas por denuncias de violaciones a derechos de ese colectivo social. A continuación, se desarrollará el tema del ingreso de las mujeres en las Fuerzas Militares y la cuestión de la jerarquía y el estricto respeto a las normas militares, perjuicios y no aceptación de los homosexuales en las Fuerzas Armadas de Brasil.

El abordaje de estos temas se constituye de fundamental relevancia pues la experiencia brasileña, de constitución de un régimen democrático aún es ineficaz en la protección de derechos pertenecientes a ese grupo social de tratamiento igualitario en relación a los demás, sea a través de una condenación legal de un Ordenamiento Jurídico brasileño (Código Penal Militar) o por acciones de perjuicios, discriminación por parte de la sociedad en general y con la Organización Militar de Brasil.

6 L. A. BRITTO CODATO / L. NAKAMA, Pesquisa em saúde: metodologia quantitativa ou qualitativa? Revista Espaço para a Saúde. Londrina, Brasil, v.8, n.1, dezembro, 2006, pp. 34-5. Disponible en: <http://www.ccs.uel.br/espacoparasaude/ v8n1/v8n1_artigo_6_nota.pdf>. Consulta en: 16 de noviembre de 2021. 


\section{Las Fuerzas Armadas de Brasil}

En Brasil, las Fuerzas Armadas son divididas y compuestas por el Ejército, Marina y de la Aeronáutica. Son instituciones nacionales permanentes y deben debido a los parámetros constitucionales, cuidar y defender el país en lo que se refiere a su seguridad territorial, así como la manutención de sus poderes (de la Carta Magna de 1988). Es válido recordar que estas Fuerzas están subordinadas al Ministerio de la Defensa brasileño.7 Según la Constitución brasileña, en su artículo 142: las Fuerzas Armadas son instituciones nacionales permanentes y regulares, organizadas con base en la jerarquía y disciplina, bajo la autoridad suprema del Presidente de la Republica y están destinadas a la defensa de la Patria, a la garantía de los poderes constitucionales y, por iniciativa de cualquier de estos, de la ley y del orden.

Este estudio tiene como finalidad verificar como las Fuerzas Armadas de Brasil se adecuan a los clamores democráticos de igualdad de trato entre los ciudadanos brasileńos, buscando retratar la situación de las mujeres y hombres, así como está la situación de las orientaciones sexual (homosexuales - gais o lesbianas, bisexuales) y las identidades de género (transgéneros) en las Fuerzas Armadas Brasileńas.

Discusiones semejantes han surgido cuando las mujeres han comenzado pleitear su participación militar. El fuerte ideario masculino impositivo ha traído las más variadas justificativas para que las mujeres no pudiesen ser incorporación en las Fuerzas Armadas. ${ }^{8}$ Llama la atención que la Marina ha sido la primera institución brasileña que ha permitido la participación de mujeres en funciones en sus dependencias, lo que nos parece incoherente la permanencia de material con índole prejudicial y de trato desigual entre hombres y mujeres. ${ }^{9}$ Hecho que demuestra un aislamiento y una forma de discriminación cuanto a la participación femenina en las Instituciones Militares brasileñas, dónde se mantiene una exaltación de un modelo paternalista ${ }^{10}$, de bases masculinizadas, de la imposición de la fuerza física y jerarquía del hombre sobre la igualdad de trato con las mujeres.

Cuando se habla de la situación de las mujeres en las Fuerzas del Ejército brasileño, no se notan muchas diferencias cuanto al ejemplo anterior de la Marina. En este segundo ejemplo, el propio lema de la Institución militar ya demuestra el estereotipo favorito para justificar la supuesta superioridad del hombre. ${ }^{11}$

7 BRASIL. O que é o Ministério da Defesa. Disponible en: <https://www.defesa.gov.br/index.php/o-que-e-o-md-ministro. html>. Consulta en: 16 de noviembre de 2021.

8 C. RODRIGUES SILVA, Mulheres em Armas. A construção de feminilidades e masculinidades nas Forças Armadas brasileiras. VIII Reunión de Antropología MERCOSUR GT 16 - Gênero em Situações de Contato: Fluxos e Processos de Atribuiçáo de Identidades. São Paulo/SP, Brasil, p. 5.

9 C. RODRIGUES SILVA, Mulheres..., op. cit., p. 5.

10 C. RODRIGUES SILVA, Mulheres..., op. cit., p. 7.

11 En Brasil, el Ejército lleva como tema: "Brazo fuerte, mano amiga". Con base en estas ideas, se nota que: la identidad femenina que ha sido creada bajo el argumento de la fragilidad de este colectivo, lo que atestaría el cometimiento de restricciones, es decir, que coloca la mujer en un sitio en que se debe ser defendida en cualquier situación, en caso de necesidad por la guerra, pero nunca como un agente directo del ejercicio de la violencia. M. C. D' ARAUJO, Pós-modernidade, sexo e gênero nas Forças Armadas. Rio de Janeiro, Brasil, p. 75. Disponible en: <http://www.ndu.edu/chds/journal/PDF/2003/dAraujo-essay.pdf >. Consulta en: 20 de noviembre de 2021.

Ese argumento también se encuentra en las palabras de un ex militar (Coronel jubilado) del Ejército brasileño que ha sido entrevistado por este ensayo científico, en sus palabras: la incorporación de las mujeres en las organizaciones militares ha sido una grande problemática, pues hemos tenido que realizar muchos cambios estructurales tanto en los espacios fisicos de los cuarteles (dormitorios, baños, gimnasio) y eso ha sido muy oneroso, han sito todos gastos desnecesarios. En mi opinión, las mujeres por no tener nascido para eso, deberían quedar en casa, cuidado de la familia, casa, hijos y del marido, que tiene condición suficiente para trabajar y llevar el dinero a casa. La mujer no necesita pasar por esa experiencia. Yo lo he hecho de esta manera, mi mujer se quedó en casa y no protestaba y yo le hacía los caprichos que pedía a mi (A.J.M-Marabá - Pará-Brasil. 2011). Esta entrevista tiene que ver con la dificultad que tiene la pareja y la familia del militar en muchos de los casos en encontrar un trabajo, pues 
En este sentido, destacase el ejemplo de Maria Quitéria de Jesus ${ }^{12}$, patrona del Cuadro Complementar de Oficiales del Ejército brasileño, una mujer que había sido obligada a vestirse como hombre para poder pertenecer al régimen de artillaría de la institución. Una mujer que ha luchado con fervor y fuerza por la independencia de Brasil, más específicamente en el Estado de Bahía. Su participación ha sido reconocida por sus compañeros y por la sociedad en general, otorgándole la posibilidad de utilizar un arma (espada). ${ }^{13}$

También se nota la existencia del respeto incondicional en la cual la jerarquía y al respeto a las normas de la Institución (disciplinares), que condicionan la labor, la profesión con la vida. Estas ideas están previstas en el reglamento de la Fuerza Armadas, Marina, Ejército ${ }^{14}$ y Fuerza Aérea de Brasil ${ }^{15}$. Con base en esas ideas, está clara la situación de la imposición unilateral de los Organismos Militares en relación a sus miembros, hecho ese que imposibilitaría cualquier manifestación contraria a los padrones establecidos anteriormente y que condiciona la participación de las mujeres en un lugar desigual en las Fuerzas Armadas. ${ }^{16}$

De otro modo, la historia ha demostrado que los valores sociales, culturales pasan por modificaciones a lo largo de la propia vida humana, con eso se puede decir que tendencias surgen y que modifican situaciones de intolerancia ${ }^{17}$, es decir que actualmente las mujeres luchan por un reconocimiento de su condición de ser mujer y tener una igualdad de trato en relación a los hombres. ${ }^{18}$

Otro dato que merece ser visualizado es que se intentamos localizar cualquier tema sobre orientaciones sexuales (homosexual, bisexual) e identidad sexual (transexual) dentro de las páginas oficiales de las Fuerzas Armadas brasileñas, las tentativas se hacen infructíferas.

En este sentido, es válido reconocer que las primeras barreras vienen siendo removidas, tanto para la situación de las mujeres ${ }^{19}$, así como para las personas que tienen diferentes identidades de género. El camino se hace complicado, lleno de preconceptos y discriminaciones. Además, estas mismas personas traban una lucha diaria por su auto-aceptación de su condición de minoría victimada por los más diversos motivos (religiosos, ideologías, culturas, política, económico, social, biológico). Así, como también, de ser aceptados por sus familiares, amigos, compañeros de trabajo, estudios y en general en sociedad.

Se hace viable la utilización de un ejemplo para aclarar esa idea supra citada:

cómo es notorio, los militares están en continuo traslados, lo que imposibilitan que sus parejas puedan también conciliar un trabajo estable o de larga duración, otros problemas también son enfrentados, por ejemplo: la formación del patrimonio familiar es extremadamente dificultada, la educación de los hijos es perjudicada, el ejercicio de actividades remuneradas por conjugue del militar se queda prácticamente impedida y el núcleo familiar no establece relaciones de larga duración y permanentes en la ciudad en que reside, porque allí, normalmente pasará 3 años. BRASIL. Características da Profissão Militar. Disponible en: <http://www.exercito.gov.br/web/guest/caracteristicas-da-profissao-militar>. Consulta en: 20 de noviembre de 2021.

12 BRASIL. Maria Quitéria de Jesus. Disponible en: <http://www.exercito.gov.br/web/ingresso/linha-do-tempo>. Consulta en: 20 de noviembre de 2021.

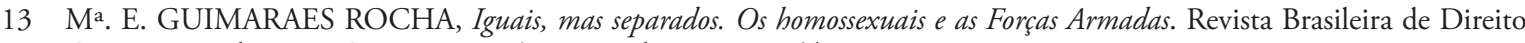
Constitucional - RBDC no 17 - Jan./Jun. Brasil, 2011, p. 164.

14 BRASIL. Características da Profissáo Militar. Disponible en: <http://www.exercito.gov.br/web/guest/caracteristicas-daprofissao-militar>. Consulta en: 20 de noviembre de 2021.

15 BRASIL. Força Aérea Brasileira. Disponible en: <http://www.fab.mil.br/portal/capa/index.php?page=quemequem>. Consulta en: 20 de noviembre de 2021.

16 BRASIL. Exército Brasileiro. Disponible en: <http://www.exercito.gov.br/02ingr/Profmili.htm\#2>. Consulta en: 20 de noviembre de 2021.

17 M. A. GONZÁLEZ BUSTOS, La Mujer ante el siglo..., op. cit., p. 35.

18 M. C. D' ARAUJO, Pós-modernidade..., op. cit., p. 75. Texto. Consulta en: 20 de noviembre de 2021.

19 M. C. D' ARAUJO, Pós-modernidade..., op. cit., p. 75. Texto. Consulta en: 20 de noviembre de 2021. 
En el punto final de mi infancia y adolescencia en 1991, cuando he tenido que alistarme en las Fuerzas Armadas. Como aún dependía financieramente de mi padre, hecho que me atormentaba, he pensado en la posibilidad de juntarlas dos cosas: usar el servicio militar para comenzar a construir mi vida, conquistar mi independencia. ${ }^{20} 21$

Es pertinente la ejemplificación usada pues retrata la idea que muchos heterosexuales tienen sobre los homosexuales. Para ellos, los homosexuales representarían una amenaza a la normalidad del cuadro de militares, pues los de orientación del deseo homosexual no pueden controlar sus deseos y que son una amenaza para todos los compañeros, que estarían en desacuerdo con las normas morales predominante heterosexual, que las personas LGBTs (lesbianas, gais, bisexuales y transgéneros) son todos pervertidos, lo que les impide de desarrollar las actividades exigidas para el cargo militar. ${ }^{22}$ Otro argumento encontrado es que los compañeros militares no obedecerían a las órdenes de un militar homosexual en jerarquía superior, una vez que supuestamente las personas con orientación homosexual no tienen una moral establecida o que sea dudosa, lo que hace con que los compañeros militares no acepten ser liderados por una persona gay o lesbiana.

Cuando se trabaja con la imagen de las mujeres en las Fuerzas Armadas, algunos militares interpretan la condición de la mujer como algo frágil, carente de fuerza, relacionando con características físicas que le imposibilitarían supuestamente de ejecutar funciones o tareas típicamente de los hombres (correr con armamentos, ejecutar actividades en selvas, pilotar e etcétera). ${ }^{23}$ De otro modo, al tratar de los homosexuales en el colectivo militar, los problemas no están restrictos a cuestiones físicas de impedimentos como ocurre con las mujeres, pero algo peor es la indiferencia, o el sentimiento de asco hipoteco generado en tener un compañero no heterosexual en el trabajo. ${ }^{24}$

Actualmente, en Brasil, las mujeres ya están incorporadas en el cuadro permanente, pero todavía no les he permitido llegar a los niveles más elevados de la carrera militar, pues, en estos casos, el prejudicio y discriminación en relación a las mujeres aún les hace estar sumisas y en una posición de trato inferior en relación a los hombres, es decir, la manifestación clara de la

20 F. ALCÂNTARA FIGUEIREDO, Soldados não choram: a vida de um casal homossexual no Exército do Brasil. Depoimento a Roldão Arruda. São Paulo, Brasil, 2008, Editora Globo, pp. 63-4.

21 Con base en esta argumentación la homosexualidad todavía es vista socialmente como un grave problema moral, como un desorden, enfermedad, una constante amenaza a la integridad y harmonía de los considerados "normales" o heterosexuales predominantes. Según la declaración de un militar de la Marina brasileña de Rio de Janeiro en 2011: Hoy en Marina, en general, hay un montón de gais en el armario. Menos mal que junto a mi no hay ninguno, que lo sepa yo, pues tener un compañero homosexual sería todo un problema, trabajar con un maricón en misión maritima y estar varios meses embarcado me saldría un verdadero martirio, pues todos los gais hacen de todo para conquistar un hombre heterosexual. Yo soy macho, hombre y no me van los otros chicos. Se otro hombre intentase tirarse a mi, le daría una paliza, pues estas libertinajes no hacen parte de mi esencia masculina.

22 De manera distinta a ese estereotipo criado para los homosexuales, es interesante la declaración de la médica residente lesbiana, que ha realizado trabajo para las Fuerzas Armadas del Ejército brasileño en Marabá - Pará en 2007. Según su declaración: Cuando entré para el Ejército, para desarrollar mi actividad laboral como residente, no me lo esperaba pasar tan bien por esta experiencia. Siempre he vivido en la capital de mi provincia y tener que desplazarme a un sitio del interior (...). No sabia que iría encontrar por allí, además siendo una mujer en el medio de un montón de hombres, que medo me daba a mí. Yo compartía casa con otros dos (chico y chica) residentes, que también trabajaban para la misma institución militar. Allí me enamoré de mi compañera de casa. Nadie sabia de nosotras y durante los dos años que me quedé en la ciudad, llevamos un relacionamiento muy bonito. Nunca escuche ningún comentario malévolo o discriminatorio por ser mujer. Teníamos claro que respetar las órdenes y la jerarquía típica militar, pero no era un problema, siempre he sido tratada muy bien y no me puedo quejar.

23 C. RODRIGUES SILVA, Mulheres..., op. cit., p. 8.

24 Las mujeres son consideradas, en general, como seres que precisan ser protegidas, dentro y fuera de los cuarteles, y esto supone la exclusión en ciertas actividades consideradas de riesgo y de rigor disciplinar y, por lo tanto, masculinas. Los homosexuales, por su vez, son vistos como portadores de un desvio de comportamiento que amenaza El buen funcionamiento técnico y moral de la corporación militar o de las instituciones como un todo. M. C. D' ARAUJO, Pós-modernidade..., op. cit., p. 72. Texto. Consulta en: 20 de noviembre de 2021. 
existencia de un techo de $\operatorname{cristal}^{25}$. En lo que se refiere a las personas con orientación homosexual y bisexual dentro de las Fuerzas Armadas, las informaciones encontradas son insuficientes, lo que imposibilita concluir ideas finales sobre esa temática.

Para los homosexuales, así como para las mujeres, hablar de trabajo y de aceptación dentro de las Fuerzas Armadas aún es una difícil tarea, se hace necesaria la búsqueda a través de la enseñanza, para que las mujeres, así como para los homosexuales puedan ser respetados en sus respectivas vidas, que encuentran igualdades de oportunidades. Es importante una real implicación de toda la comunidad para que estos deseos sean concretizados como tarea común en libertad e igualdad de oportunidades. ${ }^{26}$

Para D`ARAUJO, los estudios demuestran que en algunas situaciones de privilegios, las mujeres son vistas en una situación de reconocimiento de la inferioridad y constante dependencia, de encontrar todavía obstáculos ${ }^{27}$, como en los casos de deserción de un militar, su familia no podrá ser desamparada, la esposa será tratada legalmente viuda, con derecho a pensión, en la ausencia del marido militar, cabrá a las Fuerzas Armadas la protección de la mujer. De la misma forma, en su familia, también encontramos el carácter protector militar cuando al órgano destina pensiones para las hijas solteras (solamente a las mujeres) de militares en caso de muerte del padre militar (la institución asume una función pecuniaria de un padre o un marido), o en los casos en que la "fragilidad" femenina es usada como reivindicación política por parte de los militares para mejores salarios.

Otra manifestación militar que trata de la protección femenina por la Institución es de las mujeres, una vez en las Fuerzas Armadas, no podría ser impedida de ver su familia durante meses, especialmente cuando tienen hijos, por esta razón, son excluidas de tareas que exijan viajes muy largas sin la presencia de sus familiares. La continua protección de las mujeres también prevé la creación de zonas separadas de coexistencia dentro dos Cuarteles (Instituciones militares) por cuestiones de libido sexual. ${ }^{28}$

Ser homosexual en las Fuerzas Armadas representa algo complicado y se eres mujer y

25 La terminología techo de cristal o de vidrio es usada para caracterizar un obstáculo invisible que tiene su origen en una serie de entramadas estructuras en organizaciones con participación mayoritaria de hombres, que hacen lo posible para evitar que las mujeres accedan a los puestos más altos, o sea, los últimos y más valorados. (100 palabras para la igualdad. Glosario de Términos relativos a la igualdad entre hombres y mujeres. Comisión Europea, Dirección General del Empleo, Relaciones Laborales y Asuntos Sociales, 1998). Además, hay la definición de las paredes de cristal, trata también de estructuras que impiden veladamente a las mujeres al acceso a puestos de responsabilidad, o que sectoriza su trabajo. M. D. CANCIO ÁLVAREZ, "Glosario", loc. cit., p. 307.

26 La idea primordial para la integración de mujeres y homosexuales en las Fuerzas Armadas está relacionada a una exigencia, de algo reciente, que se encuadra con los preceptos democráticos de las sociedades, así como también, de la expansión de los derechos de igualdad entre grupos distintos (ideología, raza, sexo, etnia e género diversos). M. C. D' ARAUJO, Pós-modernidade..., op. cit., pp. 71-2. Consulta en: 20 de noviembre de 2021.

27 Obstáculos estos ya mencionados tanto por D`Araujo e por Takahashi, como por ejemplo los juegos dónde las cadetes son sometidas por sus colegas/compañeros militares cuando a su apariencia física, diciendo que ellas de todos los modos llaman a la atención, una vez que la grande mayoría de los militares son hombres. Un tema que es hablado sobre la cuestión de la apariencia, se cita el pelo. Cristina Rodrigues recuerda que estos temas surgen en la década de los 90 's, con la existencia de un reglamento para la Turma de las primeras mujeres cadetes de AFA, que determinaba que las mujeres deberían llevar el pelo corto durante el proceso de formación como oficialas, es decir, durante los cuatro años de estudios. Con el tiempo, el reglamento se ha cambiado permitiendo la manutención de los pelos más largos. El reglamento más actual sigue en proceso de ratificación, pero valido decir que hay fuerte posicionamiento interno para que la obligatoriedad del pelo corto vuelva a tener vigor. Toda esta problemática tiene que ver con la propia indicación del pelo largo con la esencia de la mujer para las cadetes y cuestiones con la feminidad y la relación con la idea de la fragilidad, parece que con el pelo corto, la mujer se parecería a un hombre y a la realidad militar. De ese modo, la no aceptación sería más pequeña. Este argumento está presente en el ideario de muchos compañeros militares hombres, tema que aún representa una problemática para la incorporación de las mujeres y en trato igualitario entre los géneros en las Fuerzas Armadas brasileñas. C. RODRIGUES SILVA, Mulheres..., op. cit., pp. 11-2.

28 M. C. D’ ARAUJO, Pós-modernidade..., op. cit., pp. 75-8. Consulta en: 20 de noviembre de 2021. 
lesbiana, las represarías, los perjuicios son intensificados, lo que torna que este grupo de personas con una orientación del deseo distinta de la predominante, pase por las más variadas violaciones a sus derechos como personas humanas, a través de estereotipos forzosos.

En relación a la incorporación de mujeres en las Fuerzas Armadas, es importante llamar la atención para la incorporación sin la debida concientización para la aceptación del colectivo femenino en el Cuadro militar, junto con otros factores, como: la baja escolaridad, tratos vejatorios, exaltación de la sumisión, impunidad a violaciones de conductas, prejuicios, prácticas comunes en los cuarteles. Todas esas prácticas que pueden generar problemas significativos para las mujeres militares, como varios casos de violaciones cometidos por hombres (militares) a compañeras de profesión.

La sensación de la injusticia y de no punición a muchas acciones cometidas dentro de las atribuciones militares hace con que las mujeres se callen y que permitan casos de violencias a sus propios derechos. Muchas mujeres militares consideran que es mejor no reaccionar frente a una triste realidad de violación, pues cualquier cuestionamiento podrá servir como represalia a su futuro dentro de las Fuerzas Armadas.

Las falsas ideas estereotipadas de que los homosexuales serían responsables por sus gustos sexuales, como se pudiese escoger, pensar que todos las personas con comportamientos femeninos, en el caso de los hombres serían gais, por consiguiente, mujeres con características masculinizadas serían lesbianas, que este grupo de orientación distinto del dominante es compuesto por personas promiscuas, incapacitados de constituir familias, que son egoístas y narcisistas. Todas estas afirmaciones hacen parte del discurso de muchos heterosexuales cuando tiene que definir una persona con orientación distinta de la heterosexual. ${ }^{29}$

Anteriormente ya ha sido expuesto que las personas con una orientación del deseo homosexual pueden tener mucho más difícil para sí relacionar, pues este relacionamiento se manifiesta a las oscuras, ya que la sociedad, por muchas maneras, impide que homosexuales asuman sus relacionamientos de forma abierta ${ }^{30}$, ellos tienen que llevar una vida a escondidas. Otro tópico interesante y que debe ser aclarado, es que los hombres gais que son caracterizados como personas promiscuas no son la mayoría. ${ }^{31}$

De esta manera, se puede entender que la orientación del deseo entre homosexuales y heterosexuales es bastante amplia y no se puede nunca generalizar. Lo que acontece en muchos de los casos es el hecho de que los hombres (heterosexuales) imaginaren que, en las Fuerzas Armadas, por lo tanto, dentro de la incorporación, ellos como hombres desearían las mujeres (compañeras de profesión), más por otro lado, tienen la idea que sus mismas compañeras, por ser mujeres, no harían lo mismo, o sea: no irían a desearlos. Este es el entendimiento de muchos militares hombres.

Con una línea de raciocinio semejante, para los hombres (hetero-militares) la incorporación de gais militares significaría una amenaza constante, pues, para los heterosexuales masculinos, pasarían a ser deseados por compañeros hombres. Este pánico está presente en las argumentaciones contrarias de militares que se han asumido homosexuales o bisexuales. El mismo caso está englobado por heterosexuales (mujeres) en relación a la aceptación de lesbianas 
en las Fuerzas Armadas. ${ }^{32}$

Para fortalecer esta idea de preconcepto, se usan las frases siguientes: Con más este camino en dirección a la libertad sexual dentro de las Fuerzas Armadas, sería obligatoria las peleas con el servicio militar. Ningún padre estaría tranquilo en saber que su hijo, durante cinco días de acampamiento, estaría durmiendo en una tienda de campaña con un compañero homosexual sin reclamar, pues se lo hace, recibiría una punición por discriminación ${ }^{33}$ sexual. ${ }^{34}$ Otro comentario con prejuicio es atribuido a un comandante da Marina inglesa, que tendría solicitado baja de sus actividades laborales. Al ser indagado por los motivos de su decisión, él ha contestado que: cuando ha comenzado a servir la Marina, el homosexualismo no era permitido, ahora que se tornó algo tolerable, me he marchado antes que sea obligatorio. ${ }^{35}$ Esta manifestación atesta todo un posicionamiento en contra de la aceptación de las personas LGBTs dentro de las Instituciones Militares en Brasil, siendo, por supuesto, toda una manifestación de práctica discriminatoria. 1

\section{Los argumentos en contra}

Se notan que los argumentos que se manifiestan contrarios a la incorporación de homosexuales en el cuadro de militares están basados en creencias culturales o en argumentaciones científicas antiguas que retrataban en muchos de los casos, la homosexualidad como algo prejudicial, anormalidad, enfermedad, etcétera. Escusas estas, que atestaban una supuesta imposibilidad de esta existencia para la buena moral y a la orden de la incorporación militar afectada por el servicio de un militar asumido homosexual, su participación seria vista como una amenaza a la integridad corporativa y jerárquica de las Fuerzas Armadas. Con este entendimiento se le atribuye la idea de desorden, de inmoralidad, anormalidad a la homosexualidad, a su plausible aceptación es negada y con eso, toda una serie de características discriminatorias toman lugar y generalizan las ideas sobre esta manifestación del deseo.

Otro argumento encontrado que sería utilizado por los defensores de la no incorporación de personas con orientación del deseo no heterosexual en las Fuerzas Armadas atestan que un homosexual o bisexual podría interferir en las líneas de combate y en la efectividad de los resultados finales, pues reducirían la cohesión de las tropas, interferirían en la disciplina del grupo y, principalmente en la moral. Citando el caso de Canadá, que ha adoptado una política de inclusión de homosexuales asumidos en sus fuerzas militares, esta experiencia resaltó justo lo contrario, es decir: que no existe ninguna evidencia que la presencia de gais o lesbianas asumidos en la institución militar canadiense representase cualquier tipo de alteración en los aspectos de la vida militar o en el rendimiento del grupo ${ }^{36}$. En este sentido, no fueron encontrados problemas en el reclutamiento, tampoco ha incidido en la diminución de la cohesión del grupo, mucho menos en la moral militar o en la efectividad organizacional de la institución militar canadiense.

32 M. C. D’ ARAUJO, Pós-modernidade..., op. cit., pp.80-1. Consulta en: 20 de noviembre de 2021.

33 Para Don Paulo Evaristo Arns, cuando se habla que: discriminar es excluir, dando forma activa a La conducta y traduciendo perfectamente el significado del vocablo discriminación, pues lo que realmente representa es la exclusión de un individuo o de un grupo. J. C. MONTEIRO BRITO FILHO, Direitos Fundamentais \& Relaçöes Sociais no Mundo Contemporâneo. Direitos Humanos e Discriminação no Brasil. Curitiba, Brasil, Editora Juruá, 2005, p. 228.

34 C. F. PEREIRA. Homossexuais nas forças armadas: tabu ou indisciplina? Disponible en: <http://campus.fortunecity.com/ clemson/493/jus/m06-021.htm>. Consulta en: 22 de noviembre de 2021.

35 C. F. PEREIRA, Homossexuais nas forças..., op. cit. Consulta en: 21 de noviembre de 2021.

36 OSCE/ODIHR. Handbook on Human Rights and Fundamental Freedoms of Armed Forces Personnel. Varsovia, Polonia, 2008, pp. 130-1. Disponible en: <www.osce.org/odihr>. Consulta en: 12 de noviembre de 2021. 
Para Cristina Amich Elías, en la mayor parte del mundo, la homosexualidad sigue viviendo rodeada por la condenación (moral y social) acompañada o no por cierta tolerancia privada. Sigue siendo vista como una amenaza a modelos vitales y sociales, y la única forma de si conseguir el reconocimiento de los Derechos Humanos de los homosexuales, bisexuales o transgéneros - ya no Derechos Humanos específicos, pero la universalización efectiva de los existentes - es trabajar por el cambio en las mentalidades. Es un proceso arduo y que parece no tener fin, como acontece con las luchas por la eliminación de otros preconceptos como el sexismo y el racismo, pero es un trabajo necesario. ${ }^{37}$ Todavía son necesarios esfuerzos colectivos para verdaderos cambios de paradigmas en Brasil, como en el mundo.

\section{El marco normativo de Brasil}

En Brasil, la búsqueda por una sociedad igualitaria y justa está presente en el preámbulo de la Constitución de 1988: "[...] asegurar el ejercicio de los derechos sociales e individuales, de libertad, seguridad, de ben-estar, de desarrollo, de igualdad y justicia como valores supremos de una sociedad fraterna, pluralista y sin preconceptos [...]" Es el destino fundamental del Estado democrático y de un ideal republicano.

Es interesante recordar que las ideas de perjuicio y discriminaciones supra citadas son originarias a lo largo de los siglos, acompañando la propia historia de la humanidad, haciendo con que las personas que integran una determinada sociedad se manifiestan de una manera o de otra, favorable o contraria a realización de conductas con carácter de aislamiento excluyente (social, moral, político, económico, sexual, cultural, religioso e etcétera). Es decir, que los integrantes de la sociedad estarán o no a favor de una participación ciudadana real, con efectiva participación, amplia, fraterna, feliz e libre entre todos sus miembros, dotados de derechos y deberes en igualdad de participación o contrarios a esa idea, buscando justificativas para monopolizar ${ }^{38}$ estos derechos o deberes en su favor (de manera desigual) entre las personas que integran una sociedad, victimando, por así decir, preceptos de igualdad, libertad, dignidad de la persona. Preceptos estos que muchas veces están previstos y regulados en el propio ordenamiento jurídico, en éste caso, el mismo conjunto de normas legales que componen el Ordenamiento Jurídico brasileño.

Se verá en este estudio preliminar que la orientación homosexual es un hecho, un facto, una verdad existente en sociedad sea cual sea el origen de su manifestación (debido al medio en que se vive, cultural, social, de índole religiosa, espiritual, biológica - genética, psicológica y otras más. La simples manifestación de la orientación del deseo homosexual en sociedad y por así decir, la existencia de personas con esa manifestación del deseo hace con que existan relaciones de afecto sentimentales (atracciones, pensamientos, prácticas sexuales) entre personas con el mismo sexo biológico, pues en valido recordar que las personas son libres para expresar sus sentimientos, amores, emociones y también tienen el derecho de dividir sus vida con quién creen alcanzaren la felicidad e exteriorizaren sus amores.

Con base en estas ideas, el Ordenamiento Jurídico brasileño no es eficaz en el sentido de no tener norma jurídica que regule la igualdad de trato entre personas con una orientación

37 Cf. C. AMICH ELÍAS, "Cultura Homosexual...” loc. cit., p. 216.

38 M. FERNÁNDEZ ENGUITA, Las desigualdades de clase, género, etnia y ciudadanía ante la educación. Sociología de la Educación, España, Universitat de les Illes Balears, 1993. 
diferente de la mayoritaria, en este sentido la mayoritaria es la heterosexual, pues cuenta con el más grande seguimiento de la población humana. Una vez que la existencia de principios (fuentes del derecho: jurisprudencia, principios generales) hacen con que ciertas recomendaciones normativas estén en desigualdad dentro del sistema jurídico de Brasil. ¿De qué principios hablamos?

- Igualdad ${ }^{39}$ : la Carta Magna brasileña de 1988, en su artículo $5^{\circ}$ establece que todos los ciudadanos deben recibir el mismo trato. En este sentido, la CF88 ha adoptado este principio pensando en la igualdad de cualidad, una igualdad de posibilidades virtuales, es decir: todos los ciudadanos tienen derecho de trato idéntico por ley, de acuerdo con criterios albergados por el Ordenamiento Jurídico. ${ }^{40}$ De acuerdo con esa idea, las personas, ciudadanos brasileños tiene el derecho a ser tratados en igualdad de condiciones y con respeto, mismo en los casos de pertenezcan a grupos victimados históricamente de participación, las mujeres en relación a los hombres, homosexuales en relación a heterosexuales, factores de raza, religiosos e muchos otros. En este caso las mujeres y las personas con una orientación del deseo sexual diferente de la heterosexual tienen derecho a ser reconocidas, protegidas. Cuando este hecho no ocurre, existe un desprecio a eses grupos de ciudadanos, es como si ellas no importasen para el Estado brasileño y que su aislamiento participativo en los más diferentes sectores (político, social, económico e etcétera) fuese justificado. Como si fuesen ciudadanos menos importantes para el sistema. Por así decir, conductas como estas deben ser combatidas e evitadas, justo para que el principio de la igualdad de trato no sea vulnerado. ${ }^{41}$

- Principio de la libertad: las relaciones homoafetivas son un hecho en la sociedad brasileña y tener esa manifestación del deseo no representa estar en desacuerdo con el Ordenamiento Jurídico Brasileño. Es importante recordar que la libertad está en hacer lo que la ley no imposibilitar hacer, es tener autonomía para realizar conductas privadas hasta dónde no violen los derechos de los otros ciudadanos. Según Alexandre de Moraes: El Estado democrático defiende el contenido esencial de la manifestación de la libertad que es asegurada tanto en lo aspecto positivo, es decir: protección de la exteriorización de la voluntad. ${ }^{42}$ En este sentido, el Estado brasileño no es agente capacitado para violar

39 El principio de la igualdad camina junto con el principio de la idéntica relevancia dónde no se puede jamás estar disociado del principio de la justicia, en su sentido más puro, no existe igualdad juridica en el no derecho. Cuando se niegan derechos fundamentales, entre ellos lo de la sobrevivencia, mediante percebimiento de beneficios por jubilación, las personas que son de sexos diferentes, lograrían éxito en tenerlos, emerge un no derecho, moviéndose en sentido contrario al del Poder Constituyente de si proteger con la igualdad al editar la Constitución Federal brasileña de 1988. El principio de la igualdad es violado cuando la desigualdad de trato surge como arbitraria. Arbitrio ese que sería condición necesaria y suficiente de violación del principio de la igualdad. SUPERIOR TRIBUNAL DE JUSTIÇA- Direito Previdenciário. Pensão por Morte. Processo: 395.904 (2001/0189742-2). RESP - Recurso Especial. Relator: Ministro Hélio Quaglia Barbosa. Recorrente: Instituto Nacional do Seguro Social - INSS. Recorrido: XXX. J. CEZÁRIO, op. cit., pp. 111-144.

40 A. MORAES, Direito Constitucional. 5a Edição, São Paulo/SP, Brasil, Editora Atlas S.A., 1999, p. 61.

41 Con ideas semejantes a las de la Constitución Federal de Brasil, también se verá en la Constitución Española: Las Cortes constituyentes, conscientes de la importancia que la igualdad tenía para el nuevo Estado social y democrático de Derecho, le dieron un trato preferente y le dedicaron varios artículos en la nueva Constitución. Si examinamos el texto de 1978 veremos que de igualdad se habla en diferentes partes y con distintas denominaciones: Nada más comenzar, la Constitución en su articulo 1.1 consagra la igualdad como valor superior del ordenamiento jurídico, asi como en el artículo 9.2, se incluye la igualdad material como un mandato de actuación dirigido a los poderes públicos que deberán promover las condiciones para que la igualdad sea efectiva y remover los obstáculos que impidan su plenitud, en el párrafo $3^{\circ}$ del articulo 9 se prohíbe la arbitrariedad en la actuación de los poderes públicos, que en conexión con los demás preceptos citados, configura la igualdad como un principio delimitador de la actividad pública, como pórtico del catálogo de derechos, el Título I CE, la igualdad se consagra como un derecho de todos ante la ley e etcétera. M. LEÓN ALONSO: "40 Respuestas desde el Derecho Constitucional” en: 161 Respuestas sobre la Violencia de Género (Desde el Derecho Constitucional, la Sociología, la Psicología y el Derecho Procesual). Salamanca, España, Caja Duero, 2008, p. 7.

42 A. MORAES, op. cit., p. 61. 
un derecho fundamental de un ciudadano en tener derechos y deberes, con posibilidad de decidir a quién depositará sus voluntades esenciales de vida, afecto, sentimientos, de compartir momentos al lado de cualquiera, también capaz de realizar estos actos de voluntad en la búsqueda de sus realizaciones, deseos, sueños.

- Principio de la dignidad de la persona humana ${ }^{43}$ : Establece esta idea que la dignidad es un bien incuantificable, que se debe proteger por el Estado brasileño y garantizado por la sociedad. Este principio estipularía que nadie en cualquier situación deberá ser tratado como medio para la realización de proyectos de otras personas, y sí, las personas deberán ser tratadas como fines en sí mismas. En este sentido, cuando trabajamos con la temática de la orientación homosexual, bisexual, heterosexual, o de la situación de las mujeres, de los transexuales, no se puede establecer límites o impedimentos en la manera de expresarse sus afectos, sentimientos, voluntades de desarrollaren tareas, trabajos, ideas e etcétera. ${ }^{44}$

La propia equiparación realizada por el Ordenamiento Jurídico militar a la homosexualidad, más específicamente en la tajante expresión de conducta típica e antijurídica, contraria a la ley, practicar acto libidinoso con características homosexuales, esta característica explícita del conjunto de normas en condenar abiertamente los homosexual, poniendo en evidencia esta terminología de forma jocosa, aún representa un grave obstáculo para la efectuación de los derechos de hombres y mujeres con orientaciones del deseo diferentes de la heterosexual.

Por otro lado, parece que en los próximos años, debido a las más recientes discusiones sobre la temática homosexual en las Fuerzas Armadas, principalmente con la visibilidad del caso de la pareja homosexual de militares de Ejército brasileño (2008), el posicionamiento de la Institución Militar sea de no impedimento a la incorporación de gais, bisexuales o lesbianas como militares y, sobre todo, de actuar con una política pública de integración y respeto a este colectivo social. Directrices estas que se manifiestan a través de:

Iniciativas como la del Ministerio de Defensa ${ }^{45}$ brasileño que estudia ablandar la legislación que pune los homosexuales en las Fuerzas Armadas, informó la Secretaria Nacional de Derechos Humanos, subordinada a la Presidencia de la República. En documento enviado a la secretaria, el ministerio se manifestó dispuesto a "discutir y proponer cambios en el artículo 235 del Código Penal Militar", que pune con hasta un año de prisión los militares que practiquen "acto libidinoso, homosexual o no". Es la primera vez que se promueve esta discusión en los círculos militares. ${ }^{46}$

43 La partida para la confirmación de los derechos de las parejas de homo-eróticos está en el contenido constitucional brasileño, que apunta como valor fundamental del Estado Democrático de Derecho, el principio de la dignidad de la persona humana (CF, Art. 1\%, III), la libertad y la igualdad sin distinción de cualquier naturaleza (CF, Art. 5o), la inviolabilidad de la intimidad y de la vida privada (CF, Art 50, X), que como asevera Luiz Edson Fachin, constituyen la base jurídica para la construcción del derecho a la orientación sexual como derecho personalísimo, atributo inherente de la persona y que, así como derecho fundamental, es un prolongamiento de derechos de la personalidad, imprescindible para la construcción de una sociedad que quiere ser libre, justa y solidaria. TRIBUNAL DE JUSTIÇA CIVIL - Dissolução de Sociedade de Fato, partilha de bens. Processo: 70005488812. AC - Apelação Civil. Relator: José Carlos Teixeira Giorgis. Procedência: Sétima Câmara Civil - Porto Alegre/ Rio Grande do Sul. Brasil. Juzgado: 25/06/2003. J. CEZÁRIO, op. cit., pp. 191-225.

44 La persona humana y su dignidad: la persona humana es el presupuesto de los derechos humanos, es el que antecede necesario, dónde los derechos humanos son lo consecuente, existe en razón de ésta y tiene su fundamento en su naturaleza, nacen con ella y para ella. Ya decía Protágoras, en el siglo V, A. C., donde ha sentenciado que: "el hombre es la medida de todas las cosas", por las cuales a él deben subordinar en el sentido de su realización.

45 R7. Defesa admite rever lei que dá margem à puniçấo de gays nas Forças Armadas. 3 de junio de 2012. Disponible en: <http://noticias.r7.com/brasil/noticias/defesa-admite-rever-lei-que-da-margem-a-punicao-de-gays-nas-forcas-armadas-20100204. html>. Consulta en: 22 de noviembre de 2021.

46 Según el general Raymundo Nonato de Cerqueira Filho aumentó la polémica en Brasil al ser preguntado en el Senado para 
Para el exministro del Supremo Tribunal Federal de Brasil, Carlos Ayres Britto: el artículo mencionado es un dispositivo que visa cohibir la práctica de cualquier ato libidinoso, homosexual o no, en las dependencias militares, la orden y la disciplina castrense, y no tiene carácter de incriminar determinada opción sexual, hasta porque, si esto ocurriera, habría inconstitucionalidad por discriminación atentatoria al artículo 3º, inciso IV, de la Carta Magna brasileña. ${ }^{47}$

El problema encontrado en la redacción de este texto legal está en la explícita forma de especificación, dónde al tajar la homosexualidad, ya se cría una situación discriminatoria en relación a ella. No se debería distinguir los actos libidinosos. Si ellos son considerados prohibidos, debería permanecer un texto que no incentivase el conflicto y el preconcepto. Con base en este argumento que se busca, actualmente, la retirada del término homosexual de este artículo. ${ }^{48}$

En Brasil, el artículo 235 del Código Penal Militar de 1969, establece: ser crimen "practicar, o permitir el militar que con él se practique acto libidinoso, homosexual o no, en lugar sujeto a administración". O sea, el militar no puede practicar tal "práctica libidinosa" y no puede aceptar ningún comportamiento de este tipo de un colega. Quién desobedecer la ley está sujeto a pena de seis meses a un año de prisión. ${ }^{49}$ Según la coordinadora de Promoción de los Derechos LGBTT de la Secretaria Nacional de Derechos Humanos, Mitchelle Meira, el problema del artículo está en el término "homosexual o no". Ella resalta que lo que está en discusión en la secretaria es la posibilidad de termos como estos contribuyen para el preconcepto: - No es crimen ser homosexual en las Fuerzas Armadas, lo que es crimen es el acto libidinoso. Entretanto, al especificar el "homosexual", se refuerza un abordaje discriminatorio en el artículo 235. Por esto la demanda para la retirada del término homosexual de la ley. ${ }^{50}$

Así se puede atestar que existe todavía una previsión normativa que discrimina a las personas por motivo de orientación sexual dentro de las Fuerzas Armadas de Brasil. Por esta razón, todavía son necesarios más estudios que visibilicen el problema en favor de cambios efectivos para la igualdad de trato en el ámbito de las Instituciones militares, como también en la propia sociedad brasileńa.

\section{Consideraciones finales}

Este estudio ha aportado que la comprensión del género es originaria de la construcción social, es decir, que tiene su esencia en las reivindicaciones de los movimientos feministas (inicialmente) y que han dado una evidencia sobre los temas de género y sus implicaciones en

una vaga en el Superior Tribunal Militar (STM). Cuestionado por senadores sobre el tema, el general afirmó que: está comprobado que homosexuales no consiguen comandar. R7. Defesa admite rever lei que dá margem à puniçáo de gays nas Forças Armadas. 3 de junio de 2012. Disponible en: <http://noticias.r7.com/brasil/noticias/defesa-admite-rever-lei-que-damargem-a-punicao-de-gays-nas-forcas-armadas-20100204.html>. Consulta en: 22 de noviembre de 2021.

47 J. CEZÁRIO, op. cit., pp. 281-2.

48 En el año de 2002, el Executivo ha encaminado el proyecto de ley al Congreso Nacional sobre los Derechos Humanos en que se propuso la alteración del artículo 235 del Código Penal Militar. La propuesta era de abolir las palabras: pederastia y homosexuales de los regimientos de disciplina militar. $M^{a}$. E. GUIMARAES ROCHA, op. cit., p. 149.

49 En lo que di respeto al capítulo VII (De los crímenes sexuales) del Código Penal Militar Brasileño, en su Artículo 235: Practicar, o permitir el militar que con él se practique acto libidinoso, homosexual o no, en lugar sujeto a administración militar. Pena - detención, de seis meses a un año. BRASIL. DECRETO-LEI No 1.001, DE 21 DE OUTUBRO DE 1969. Disponible en: <http://www.planalto.gov.br/CCIVIL_03/Decreto-Lei/Del1001.htm>. Consulta en 21 de noviembre de 2021.

50 R7. Defesa admite rever lei que dá margem à punição de gays nas Forças Armadas. 3 de junio de 2012. Disponible en: $<$ http://noticias.r7.com/brasil/noticias/defesa-admite-rever-lei-que-da-margem-a-punicao-de-gays-nas-forcas-armadas-20100204. html>. Consulta en: 22 de noviembre de 2021. 
la sociedad. Implicaciones estas que tienen que ver con los diversos roles que la terminología podrá asumir, así como en relación con las diferentes ámbitos, sean en las ciencias humanas, biológicas y en muchas otras. Conjuntamente con estos movimientos se ańaden otros grupos, también victimados en el tiempo, por la exclusión social participativa, evidenciando toda una problemática vivida por grupos que se encuentran en situaciones de desigualdades, solamente por pertenecer determinadas características (fisiológicas o psicológicas), roles construidos, que les dificulta la efectiva participación en derechos y deberes de manera justa entre todos los ciudadanos.

En la actualidad que los grupos de personas excluidos también son un producto de la construcción histórica y que, además, tienen su importancia para la sociedad. Por este motivo, estos grupos, antes aislados de participación, deben tener su ciudadanía respetada por el mero hecho de ser personas y merecen una igualdad de trato en derechos y deberes, que deben ser garantizados a todas las personas, sin distinción por lo motivo que sea. En este sentido, se llama la participación del Estado, a través de sus mecanismos institucionales, como Entidad responsable, así como la instrumentalización de una acción en conjunto de los más variados sectores públicos, privados, Organismos no pertenecientes al Gobierno brasileńo, la sociedad civil en mantener la harmonía social. Con esa idea se muestra cristalina la necesidad del respeto a la diversidad y dignidad humana.

Con el estudio se ha logrado la comprensión que variados son los motivos que contribuyen para la victimización tanto de la participación femenina así como de las personas con una orientación homosexual en la sociedad brasileña, lo que representa una dificultad en la efectuación de derechos y deberes, imposibilitando la igualdad de trato entre todos los ciudadanos.

La investigación ha trabajado con determinados objetivos para la consolidación de mecanismos para la integración de mujeres y homosexuales en el cuerpo de las instituciones militares en Brasil. En ese sentido, se evidenciará que la inclusión de grupos excluidos en sociedad aún está ligada a variados factores cruciales: 1) La necesidad de cambios en la definición de subordinación a la que están sujetos los grupos de mujeres, así como la temeraria temática de la homosexualidad y de la sexualidad de las personas; 2) La adecuación de los dispositivos jurídicos y normativos para evitar que grupos sociales sean desamparados en sus derechos y deberes. En ese sentido es importante la creación de preceptos legales que penen las actitudes que violen los derechos de grupos victimados por perjuicios y discriminaciones variados y la importante constitución de entidades de apoyo, de vigilancia y control, como por ejemplo: las fiscalías, atestando la eficacia de esas normas y adecuación de las mismas a las realidades sociales.

\section{Referencias}

AMICH ELÍAS, "Cultura Homosexual, Sujeto. Homosexual y Derechos Humanos" en: FORO. Revista de Ciencias Jurídicas y Sociales, Ensayos, No 5. Madrid. España, Nueva Época, 2007.

A. MORAES, Direito Constitucional. 5a Edição, São Paulo/SP, Brasil, Editora Atlas S.A., 1999.

A. OLIVEIRA, Curso de Direitos Humanos. Rio de Janeiro, Brasil, Editora Forense, 2000. 
BRASIL. Características da Profissão Militar. Disponible en: <http://www.exercito.gov.br/web/ guest/caracteristicas-da-profissao-militar>. Consulta en: 20 de noviembre de 2021.

BRASIL. DECRETO-LEI No 1.001, DE 21 DE OUTUBRO DE 1969. Disponible en: <http:// www.planalto.gov.br/CCIVIL_03/Decreto-Lei/Del1001.htm>. Consulta en 21 de noviembre de 2021.

BRASIL. Exército Brasileiro. Disponible en: <http://www.exercito.gov.br/02ingr/Profmili. htm\#2>. Consulta en: 20 de noviembre de 2021.

BRASIL. Força Aérea Brasileira. Disponible en: <http://www.fab.mil.br/portal/capa/index. php?page=quemequem $>$. Consulta en: 20 de noviembre de 2021 .

BRASIL. Maria Quitéria de Jesus. Disponible en: <http://www.exercito.gov.br/web/ingresso/ linha-do-tempo>. Consulta en: 20 de noviembre de 2021.

BRASIL. O que é o Ministério da Defesa. Disponible en: <https://www.defesa.gov.br/index. php/o-que-e-o-md-ministro.html>. Consulta en: 16 de noviembre de 2021.

C. F. PEREIRA. Homossexuais nas forças armadas: tabu ou indisciplina? Disponible en: <http:// campus.fortunecity.com/clemson/493/jus/m06-021.htm>. Consulta en: 22 de noviembre de 2021.

C. RODRIGUES SILVA, Mulheres em Armas. A construção de feminilidades e masculinidades nas Forças Armadas brasileiras. VIII Reunión de Antropología MERCOSUR GT 16 - Gênero em Situações de Contato: Fluxos e Processos de Atribuição de Identidades. São Paulo/SP, Brasil.

F. ALCÂNTARA FIGUEIREDO, Soldados não choram: a vida de um casal homossexual no Exército do Brasil. Depoimento a Roldão Arruda. São Paulo, Brasil, Editora Globo, 2008.

F. LÓPEZ SÁNCHEZ, Homosexualidad y familia. Lo que los padres, madres, homosexuales y profesionales deben saber y hacer. $1^{\text {a }}$ Edición, Barcelona. España, Editorial GRAÓ, junio de 2006.

J. C. MONTEIRO BRITO FILHO, Direitos Fundamentais \& Relaçōes Sociais no Mundo Contemporâneo. Direitos Humanos e Discriminação no Brasil. Curitiba, Brasil, Editora Juruá, 2005.

J. CEZÁRIO, Legislação e Jurisprudência LGBTTT. Brasília. Brasil, Instituto de Bioética, Direitos Humanos e Gênero e Associação Lésbica Feminista de Brasília Coturno de Vênus, Brasília, Brasil, 2007.

Ma. A. GONZÁLEZ BUSTOS, La Mujer ante el siglo XXI. Una perspectiva desde el ordenamiento jurídico-administrativo. Edición primera. Badajoz, España, Editora @becedario, 2006.

M. D. CANCIO ÁlVAREZ, “Glosario” en E. Conde Álvarez / A. Figueruelo Burrieza / L. Nuño Gómez, Estudios Interdisciplinares sobre Igualdad. Segunda Edición. Madrid, España, Iustel - Instituto de Derecho Público, 2011.

Ma. E. GUIMARAES ROCHA, Iguais, mas separados. Os homossexuais e as Forças Armadas. Revista Brasileira de Direito Constitucional - RBDC no 17 - Jan./Jun. Brasil, 2011. 
M. FERNÁNDEZ ENGUITA, Las desigualdades de clase, género, etnia y ciudadanía ante la educación. Sociología de la Educación, Espańa, Universitat de les Illes Balears, 1993.

M. LEÓN ALONSO: “40 Respuestas desde el Derecho Constitucional” en: 161 Respuestas sobre la Violencia de Género (Desde el Derecho Constitucional, la Sociología, la Psicología y el Derecho Procesual). Salamanca, España, Caja Duero, 2008.

R. RAUPP RIOS, "Homofobia na perspectiva dos direitos humanos e no contexto dos estudos sobre preconceito e discriminação," en R. Diniz Junqueira, Diversidade Sexual na Educaçâo: problematizaçóes sobre a homofobia nas escolas. Brasília, Brasil, Coleção Educação para todos, 2009.

R7. Defesa admite rever lei que dá margem à punição de gays nas Forças Armadas. 3 de junio de 2012. Disponible en: <http://noticias.r7.com/brasil/noticias/defesa-admite-rever-lei-que-damargem-a-punicao-de-gays-nas-forcas-armadas-20100204.html>. Consulta en: 22 de noviembre de 2021.

L. A. BRITTO CODATO / L. NAKAMA, Pesquisa em saúde: metodologia quantitativa ou qualitativa? Revista Espaço para a Saúde. Londrina,Brasil, v.8, n.1, dez., 2006, pp. 34-5. Disponible en: <http://www.ccs.uel.br/espacoparasaude/v8n1/v8n1_artigo_6_nota.pdf>. Consulta em: 16 de noviembre de 2021.

M. C. D' ARAUJO, Pós-modernidade, sexo e gênero nas Forças Armadas. Rio de Janeiro, Brasil, p. 72. Disponible en: <http://www.ndu.edu/chds/journal/PDF/2003/dAraujo-essay.pdf>. Consulta en: 20 de noviembre de 2021.

OSCE/ODIHR. Handbook on Human Rights and Fundamental Freedoms of Armed Forces Personnel. Varsovia, Polonia, 2008, pp. 130-1. Disponible en: <www.osce.org/odihr>. Consulta en: 12 de noviembre de 2021. 